\title{
Heat stable enterotoxin produced by Escherichia coli in acute diarrhoea
}

\author{
A GUARINO,${ }^{*}$ M ALESSIO,${ }^{*}$ L TARALLO,${ }^{*}$ M FONTANA $\dagger$ G IACONO,$\ddagger$ L GOBIO CASALI,$\S$ \\ AND S GUANDALINI* \\ ${ }^{*}$ Department of Paediatrics, University of Naples, †4th Paediatric Clinic, University of Milan, $¥$ Children’s \\ Hospital 'Di Cristina', Palermo, and §Paediatric Division, Hospital of Mantua, Italy
}

SUMMARY We screened 569 children with acute onset diarrhoea from five Italian towns for heat stable enterotoxin produced by Escherichia coli. We compared an enzyme linked immunoabsorbent assay (ELISA) with the standard suckling mouse assay for detection of the enterotoxin. A total of $31(5.4 \%)$ children were found who had strains of $E$ coli that produced heat stable enterotoxin: 26 strains were positive in both tests, four only in the suckling mouse assay, and one only in the ELISA. Compared with the suckling mouse assay the sensitivity of the ELISA was $87 \%$ and the specificity was $99.8 \%$. The mean age of the children with $E$ coli that produced heat stable enterotoxin was 22 months. Fifteen $(48 \%)$ of the children had ingested potentially contaminated food and five $(17 \%)$ had a previous contact with someone with diarrhoea. The clinical picture was milder than that described in developing countries. Faecal osmolality and the osmolal gap were consistent with a secretory diarrhoea in 12 out of $15(80 \%)$ of these children. The mean duration of the diarrhoea was five days. Heat stable enterotoxin produced by $E$ coli is a common cause of mild diarrhoeal illness in Italian children.

Diarrhoea induced by heat stable enterotoxin is the result of a multistep process involving (after small intestinal colonisation and release of heat stable enterotoxin ${ }^{1}$ ) the binding of the toxin to receptors located on the brush border of enterocytes, ${ }^{2}$ the activation of the guanylate cyclase-guanosine monophosphate (cGMP) system, ${ }^{3}$ and the resulting inhibition of sodium and chloride absorption along with the stimulation of anion and water secretion. Diarrhoea induced by heat stable enterotoxin is therefore of the secretory type, no signs of inflammation or colon involvement being usually present. $^{5}$

Escherichia coli that produce heat stable enterotoxin are among the most common aetiological agents of diarrhoea in developing countries. ${ }^{6-10}$ Scanty information is available, however, about their role in industralised countries. We have previously reported the isolation of $E$ coli that produce heat stable enterotoxin in Naples, southern Italy, from less than $1 \%$ of children with acute gastroenteritis in two series of patients. ${ }^{11} 12 \mathrm{~A}$ similar frequency has been reported in Brescia, northern Italy. ${ }^{13}$ Other investigators reported sporadic isolation from children with diarrhoea in
Finland, ${ }^{14}$ Canada, ${ }^{15}$ and the United States. ${ }^{16}$ No strains of $E$ coli that produce heat stable enterotoxin have been found in Switzerland ${ }^{17}$ or Sweden. ${ }^{18}$

Thus in industrialised countries $E$ coli that produce heat stable enterotoxin are regarded as putative agents of traveller's diarrhoe ${ }^{19}$ rather than as endemic intestinal pathogens. Accordingly, a search for these agents is not performed on a routine basis in patients with diarrhoea. The identification of heat stable enterotoxin produced by $E$ coli is currently based on the suckling mouse assay, ${ }^{20}$ which is reliable, does not require special facilities, is relatively inexpensive, but is cumbersome and time consuming. A possible alternative is the use of various DNA probes, ${ }^{21}$ which, however, require the use of radioisotopes and might give false positives. ${ }^{22}$ Thompson et al developed a competitive ELISA for heat stable enterotoxin which is rapid and does not require sophisticated equipment. ${ }^{23}$ Until now this test has never been performed on a large number of patients.

As a part of a national investigation on the incidence, aetiology, diagnosis, and clinical features in childhood enteritis by the National Study Group on Acute Diarrhoea in Childhood (coordinated by 
S Guandalini), we have screened 569 children with acute onset diarrhoea with the suckling mouse assay and the ELISA for heat stable enterotoxin produced by $E$ coli. In the present report we focus on the epidemiological and clinical features of children with $E$ coli that produce heat stable enterotoxin and the comparison between the suckling mouse assay and the ELISA for the diagnosis of diarrhoea related to heat stable enterotoxin.

\section{Patients and methods}

A total of 569 children (mean age 43 months, range: newborn to 15 years) from five towns in Italy (Milan, Mantua, Naples, Palermo, and Messina, table 1), who presented with diarrhoea of acute onset, were included in this study. Diarrhoea was defined as an unequivocal greater frequency or diminished consistency of stools, or both, in comparison with the previous usual pattern. Patients known to have received antibiotics were excluded. One hundred and seventy two children without gastrointestinal symptoms, and matched for age and season, were enrolled as controls. Clinical assessment was performed as previously described. ${ }^{12}$

The following information was collected from the parents by the physician in charge of each patient: (a) the presence of subjects with diarrhoea living in the same house in the two weeks before the onset of diarrhoea and (b) the ingestion of food by the patient known to be potentially contaminated and, specifically, uncooked mussels, eggs, and unwashed vegetables. All patients were drinking chlorinated tap water.

\section{LABORATORY METHODS}

Diarrhoea was considered in keeping with a secretory pattern when the osmolal gap [osmolality $2 \times$ (sodium + potassium concentration)] in the stool supernatant did not exceed $40 \mathrm{mmol} / \mathrm{l}$. The isolation

Table 1 Isolation rate of $E$ coli that produce heat stable enterotoxin in five Italian towns

\begin{tabular}{ll}
\hline Town & $\begin{array}{l}\text { No }(\%) \text { children with } \\
\text { E coli that produce } \\
\text { heat stable enterotoxin/ } \\
\text { No of children screened }\end{array}$ \\
\hline Milan & $19 / 201(9 \cdot 4)$ \\
Messina & $1 / 14(7 \cdot 1)$ \\
Palermo & $6 / 151(3 \cdot 9)$ \\
Naples & $3 / 99(3 \cdot 0)$ \\
Mantua & $2 / 104(1 \cdot 9)$ \\
\hline Total & $31 / 569(5 \cdot 4)$ \\
Controls & $0 / 172$ \\
\hline
\end{tabular}

and identification of enteropathogens (bacteria, viruses, and parasites) was performed as previously reported. ${ }^{24}$ Five strains of $E$ coli were pooled from each stool specimen of subjects as well as healthy controls. Strains to be tested for production of heat stable enterotoxin were stored in nutrient agar in the dark and sent to our laboratory in Naples. They were screened by the suckling mouse assay according to Giannella ${ }^{20}$ : strains were grown in casamino acid yeast extract in a shaker incubator, the cultures were centrifuged, and $0.1 \mathrm{ml}$ was injected intragastrically in mice 2-4 days of age. After three hours the mice were killed by decapitation and the ratio from gut weight divided by body weight was determined. Values greater than 0.083 were considered positive; values less than 0.075 were considered negative; intermediate results were considered doubtful and repeated. E coli strain $214 \mathrm{Cl}$, which produces heat stable enterotoxin, and an $E$ coli strain that does not served as controls.

The same supernatants were simultaneously screened for heat stable enterotoxin using an ELISA test as described by Thompson et al. ${ }^{23}$ We used antiheat stable enterotoxin monoclonal antibodies prepared against pure heat stable enterotoxin from $E$ coli strain $18 \mathrm{D}^{25}$ The standard curve was obtained with heat stable enterotoxin purified by high performance liquid chromatography and quantitated by amino acid analysis. A total of $50 \mu \mathrm{l}$ of heat stable enterotoxin-bovine serum albumin conjugate $(1 \mu \mathrm{l} / \mathrm{mg})$ in carbonate buffer, ph $9 \cdot 6$, were used to coat each well of a 96 well flat bottom microtitre plate (Limbro Eia Microtest, Flow Laboratories) as suggested. ${ }^{23}$ After 18 hours of incubation at $4^{\circ} \mathrm{C}$, the plates were washed and subsequently blocked with $1 \%$ bovine serum albumin in phosphate buffered saline for one hour at $37^{\circ} \mathrm{C}$. An eight point standard curve of pure heat stable enterotoxin was added to each plate. Pure heat stable enterotoxin and samples were mixed with monoclonals (20 C1B8) in glass tubes on ice: each well received $50 \mu \mathrm{l}$ of monoclonal antibody solution (final dilution $1: 160$ of $2 \mu \mathrm{g} / \mathrm{ml}$ stock solution) containing $5 \mu \mathrm{l}$ of bacterial supernatant. After 18 hours of incubation at $4^{\circ} \mathrm{C}$, the plates were washed and $50 \mu \mathrm{l}$ of horseradish peroxidase labelled affinity purified goat antimouse IgG, at a final dilution of 1:250 in $\mathbf{0} \cdot 1 \%$ bovine serum albumin in phosphate buffered saline, were added to each well for 15 minutes at room temperature. Plates were then rinsed and 100 $\mu \mathrm{l}$ of freshly diluted chromogenic substrate $(2 \cdot 2$ azino-diethylbenzothiazoline sulphonic acid), with $0.03 \%$ hydrogen peroxide in $0.1 \mathrm{M}$ citrate buffer, $\mathrm{pH}$ 4 , were added to each well. After an incubation of 20 minutes in the dark, plates were read by eye. Colour darker than the well containing $100 \mathrm{pg}$ of 
heat stable enterotoxin (corresponding to $20 \mathrm{ng}$ of heat stable enterotoxin/ml of bacterial culture) were considered positive. Positive strains were tested twice in both the suckling mouse assay and the ELISA.

Both monoclonal antibodies and the heat stable enterotoxin were generous gifts of Dr R Giannella, Cincinnati, Ohio. Culture media were purchased from Difco and antimouse IgG from Kierkegard and Perry. All chemicals were of analytical reagent grade.

Statistical analysis was performed by $\chi^{2}$ test and by the $t$ test where appropriate.

\section{Results}

$E$ coli strains were isolated from 541 of the 569 children with diarrhoea (95\%) and from 150 of the 172 controls $(87 \%)$. A total of $31(5 \cdot 4 \%)$ children, all belonging to the study group, had strains of $E$ coli in their intestine that produced heat stable enterotoxin. These strains were isolated in each of the five towns in which the screening was performed (table 1).

The prevalence of strains of $E$ coli that produce heat stable enterotoxin was $11 \%$ in children with infectious diarrhoea. They were the fourth most common infectious agent isolated from cases of intestinal infections after rotavirus $(47 \%)$, campylobacter $(17 \%)$, and salmonella (15\%). In nine affected patients an associated pathogen was isolated: three had rotavirus, two salmonella, two campylobacter, one rotavirus and salmonella, and one rotavirus and campylobacter. A total of 26 strains of $E$ coli were positive for heat stable enterotoxin in both ELISA and the suckling mouse assay, one only in the ELISA, four only in the suckling mouse assay (table 2). None of controls was positive for $E$ coli that produce heat stable enterotoxin by either assay. Considering the suckling mouse assay as the standard test, specificity of the ELISA was $99.8 \%$ and sensitivity was $87 \%$.

The seasonal pattern of $E$ coli that produce heat

Table 2 Comparison of the ELISA and suckling mouse assay in detecting activity of heat stable enterotoxin

\begin{tabular}{lcc}
\hline & $\begin{array}{c}\text { ELISA } \\
\text { positive }\end{array}$ & $\begin{array}{l}\text { ELISA } \\
\text { negative }\end{array}$ \\
\hline $\begin{array}{c}\text { Suckling mouse } \\
\text { assay positive }\end{array}$ & 26 & 4 \\
$\begin{array}{c}\text { Suckling mouse } \\
\text { assay negative }\end{array}$ & 1 & $660^{*}$ \\
\hline
\end{tabular}

${ }^{*}$ Including 510 patients and 150 controls with $E$ coli in the stools.

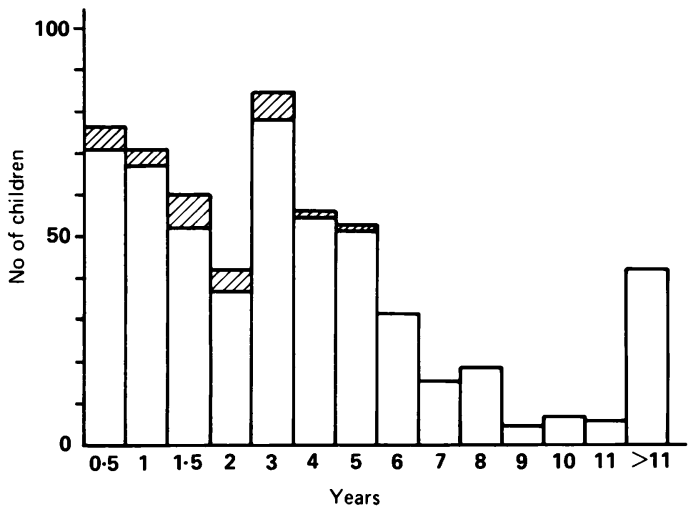

Figure Age distribution of children with E coli that produce heat stable enterotoxin $(\mathbb{Z})$ and of all other patients (ㅁ). The prevalence of diarrhoea induced by heat stable enterotoxin ranged from $5.6 \%$ to $13.3 \%$ in first 3 years of life and decreased sharply thereafter.

stable enterotoxin was as follows: $13(42 \%)$ cases in spring, five $(16 \%)$ in summer, $12(39 \%)$ in autumn, and one $(3 \%)$ in winter. The age distribution of the affected children is shown in the figure: the mean age of affected children was 22 months (range 0-63 months) whereas the mean age of all the other children in the study group was 43 months (range $0-180$ months $)(p<0 \cdot 05)$. A possible interhuman spread of infection was recorded from six $(20 \%)$ of the patients positive for $E$ coli that produce heat stable enterotoxin and from $92(17 \%)$ of all other children with diarrhoea ( $\mathrm{p}>0.05)$.

A total of $15(48 \%)$ children with $E$ coli that produce heat stable enterotoxin had previously ingested potentially contaminated food one week or less before the onset of symptoms compared with $118(22 \%)$ of all other children enrolled $(p<0 \cdot 01)$. Mean duration of diarrhoea was five days (median was $3 \cdot 2$ ); in 28 of the 31 children, however, symptomatology lasted less than seven days.

Two children were malnourished with weight below the 5th centile.

Clinical features of children with diarrhoea induced by heat stable enterotoxin produced by $E$ coli where no other pathogens were found are listed in table 3 and compared with those of all other children belonging to the study group. The incidence of both dehydration and vomiting was significantly lower in children with $E$ coli that produce heat stable enterotoxin than in all other patients. On the contrary, there were no differences in the presence of fever, abdominal pain, or associated respiratory symptoms.

In table 4 the stool characteristics of children 
Table 3 Comparison of clinical features of children who were positive or negative for $E$ coli that produce heat stable enterotoxin

\begin{tabular}{llll}
\hline & $\begin{array}{l}\text { Positive } \\
\text { No }(\%) \\
(n=22)^{*}\end{array}$ & $\begin{array}{l}\text { Negative } \\
\text { No }(\%) \\
(n=538)\end{array}$ & $p$ Value \\
\hline Dehydration & $4(18)$ & $306(57)$ & $<0 \cdot 001$ \\
Fever $\left(>38^{\circ} \mathrm{C}\right)$ & $5(23)$ & $247(46)$ & NS \\
Vomiting & $3(14)$ & $253(47)$ & $<0 \cdot 01$ \\
Abdominal pain & $7(32)$ & $226(42)$ & NS \\
'Cold' symptoms & $6(27)$ & $199(37)$ & NS \\
\hline
\end{tabular}

Nine children in whom $E$ coli that produce heat stable enterotoxin were isolated together with other enteric pathogens were excluded.

Table 4 Comparison of stool characteristics of children who were positive or negative for $E$ coli that produce heat stable enterotoxin

\begin{tabular}{lcll}
\hline & $\begin{array}{l}\text { Positive } \\
\text { No (\%) } \\
(n=22)^{*}\end{array}$ & $\begin{array}{l}\text { Negative } \\
\text { No (\%) } \\
(n=538)\end{array}$ & $p$ Value \\
\hline Watery & $14(64)$ & $360(67)$ & NS \\
Loose & $8(36)$ & $178(33)$ & NS \\
Gross blood & $0(0)$ & $253(47)$ & $<0.001$ \\
$\begin{array}{l}\text { Leucocytes } \\
\text { Mucous }\end{array}$ & $1(5)$ & $44(13)$ & NS \\
$\begin{array}{l}\text { Increased } \\
\text { osmolal gap }\end{array}$ & $6(27)$ & $291(54)$ & $<0.05$ \\
\hline
\end{tabular}

*Nine children in whom $E$ coli that produce heat stable enterotoxin were isolated together with other enteric pathogens were excluded.

positive for and negative for $E$ coli that produce heat stable enterotoxin are reported: there were no remarkable differences in the two groups besides the higher incidence of gross blood in the stools of the children who were negative. Determination of sodium, potassium, and osmolality in faeces was performed in 15 subjects: a pattern consistent with secretory diarrhoea was detected in 12 children $(80 \%)$.

All but five children received oral rehydration only: this consisted of glucose electrolyte $(60 \mathrm{mmol}$ sodium) solution. Only one child required intravenous correction of dehydration because of vomiting and severe acidosis.

Antibiotics were given to four children. All patients did well, however, and rapidly regained weight after recovery from the diarrhoea.

In three children the diarrhoea became chronic ( $>14$ days) and the presence of $E$ coli that produce heat stable enterotoxin was persistent in the stools, but it ceased spontaneously.

\section{Discussion}

Our data suggest that heat stable enterotoxins produced by $E$ coli are a common cause of diarrhoea in paediatric patients in Italy, and that the relative frequency is presently increasing in comparison with the previously available information. ${ }^{1-13}$ The decreasing incidence reported in the total number of cases caused by other better known pathogens (probably because of better prevention) is possibly responsible, at least in part, for the observed relative increase in the incidence of diarrhoea caused by heat stable enterotoxin in our country.

Strains of $E$ coli that produce heat stable enterotoxin were isolated from all five towns in which the investigation was carried out; this suggests that it is endemic in Italy. No outbreaks occurred during the study period. The history of previous ingestion of potentially contaminated food in about $50 \%$ of the affected children suggests that food is likely to be the predominant source of infection. This assumption is supported by previous reports of the role of contaminated food in the endemic and the epidemic spread of enteritis caused by heat stable enterotoxin produced by $E$ coli. ${ }^{26-28}$

Transmission through contacts who had diarrhoea is thought to be rare, as a large inoculum is apparently necessary to induce diarrhoea. ${ }^{29} \mathrm{We}$ have no clear evidence of such a transmission in our series as we did not attempt to isolate $E$ coli that produce heat stable enterotoxin from potential contacts. The record of contacts with subjects who had diarrhoea, in any event, in affected patients was similar to that of all children enrolled in the study group.

Spring and autumn peaks in detection were different from that usually reported in developing countries, where the prevalence of isolation is found in the warm and humid season. ${ }^{27}$

The mean age of affected children was younger than that of the study group. The increased susceptibility of young infants to diarrhoea induced by heat stable enterotoxin has been previously reported in developing countries. ${ }^{630}$ The higher sensitivity of young children to the enterotoxin is supported by recent laboratory investigations. Cohen $e t$ al have in fact shown in an animal model that the number of receptors for heat stable enterotoxin is increased in young subjects. ${ }^{31}$ One of the authors (AG) has reported that in children heat stable enterotoxin produced by $E$ coli induces an increase in guanylate cyclase activity, whose magnitude is maximal in the newborn and then decreases with an age related pattern. ${ }^{32}$ Therefore the increased susceptibility and severity observed seems to be related to the state of intestinal development.

The overall clinical picture of diarrhoea induced by heat stable enterotoxin was that of a mild to moderate diarrhoea, far less severe than that 


\section{Guarino, Alessio, Tarallo, Fontana, Iacono, Gobio Casali, and Guandalini}

reported in developing countries. Furthermore, the incidence of dehydration was significantly lower in patients with heat stable enterotoxin produced by $E$ coli than in patients with other diagnosis. This was somehow surprising in view of the present understanding of the pathophysiology of diarrhoea mediated by heat stable enterotoxin as a diarrhoea of the secretory type. ${ }^{33}$ It should be noted, however, that all patients, with one exception, did well with oral rehydration only. The effectiveness of oral solution in preventing dehydration was due, at least in part, to its prompt administration soon after the onset of diarrhoea. In this respect it is of interest to note that values of faecal sodium and potassium and osmolality were consistent with a secretory diarrhoea in about $80 \%$ of our patients.

Mean duration of symptomatology in our study group was not different from that reported in developing countries, ${ }^{634}$ despite the different incidence of malnutrition in the two population samples. Three children had a protracted diarrhoea, which in one case lasted longer than one month. This unusual presentation of diarrhoea induced by heat stable enterotoxin suggests that the enterotoxin should be considered in the differential diagnosis of chronic diarrhoea.

The reported mortality rate associated with diarrhoea caused by heat stable enterotoxin is variable in developing countries. ${ }^{35}$ All of our patients did well thus suggesting that diarrhoea induced by the enterotoxin: (a) does not itself have a high virulence, (b) can be effectively counteracted by prompt rehydration, and (c) is probably less severe in well nourished children.

The ELISA test used was rapid, easy to perform, reliable, and did not require sophisticated equipment. Four strains of $E$ coli that produce heat stable enterotoxin were not detected by the ELISA whereas one was positive in the ELISA only. We have characterised an enterotoxin produced by Klebsiella pneumoniae, which behaves like the heat stable enterotoxin produced by $E$ coli, but is not detected by the ELISA (manuscript in preparation). It is therefore possible that some differences in the primary sequence of the family of heat stable enterotoxins could affect their detection by monoclonal antibodies raised against pure heat stable enterotoxin from $E$ coli. We do not have an explanation for the strain that was positive exclusively in the ELISA.

Even though the ELISA test did not detect about $10 \%$ of the heat stable enterotoxins detected by the suckling mouse assay, we believe that this is a good alternative to the latter and to the DNA probe, particularly when large numbers of samples are to be screened or if animals or radioisotopes are not available.

\section{Conclusion}

Heat stable enterotoxin produced by $E$ coli is a common cause of acute watery diarrhoea in Italy. Contaminated food is likely to be the main source of infection. Younger infants are more susceptible to diarrhoea caused by heat stable enterotoxin produced by $E$ coli. The symptomatology is usually milder in Italy than that described in developing countries. The symptomatology is milder than that associated with other aetiologies. Heat stable enterotoxin can be responsible for chronic diarrhoea. The ELISA test with monoclonal antibodies is a convenient and reliable tool for diagnosis.

The authors acknowledge the members of the National Study Group on Acute Diarrhoea in Childhood of the Italian Society of Paediatrics for providing information about their patients; Dr R Giannella (Division of Digestive Diseases, University of Cincinnati, Ohio) for reviewing the manuscript; and Isabella Continisio for secretarial help.

\section{References}

${ }^{1}$ Boedecker EC. Enterocyte adherence of Escherichia coli: its relation to diarrheal diseases. Gastroenterology 1982;83:489-92.

2 Giannella RA, Luttrell M, Thompson M. Binding of Escherichia coli heat-stable enterotoxin to receptors on rat intestinal cells. Am J Physiol 1983;243:G36-41.

3 Field M, Graf LH, Smith PL. Heat-stable enterotoxin of Escherichia coli: in vitro effects of guanylate cyclase activity, cyclase GMP concentration, and ion transport in small intestine. Proc Natl Acad Sci USA 1978;75:2800-4.

${ }^{4}$ Rao MC, Guandalini S, Smith PL, Field M. Mode of action of heat-stable $E$ coli enterotoxin: tissue and subcellular specificities and role of cyclic GMP. Biochim Biophys Acta 1980;632:660-72.

${ }^{5}$ Moon HW, Kohler EM, Schneider RA, Whipp SC. Prevalence of pilus antigens, enterotoxin types, and enteropathogenicity among K88-negative enterotoxigenic Escherichia coli from neonatal pigs. Infect Immun 1980;27:220-30.

${ }^{6}$ Black RE, Brown KH, Becker S, Abdul Alim ARM, Huq I. Longitudinal studies of infectious diseases and physical growth of children in rural Bangladesh. II. Incidence of diarrhea and association with known pathogens. Am J Epidemiol 1982;115: 315-24.

7 Guerrant RI, Kirchoff LV, Shields DS, et al. Prospective study of diarrhel illnesses in Northeastern Brazil: patterns of disease, nutritional impact, etiologies and risk factors. $J$ Infect Dis 1983;148:986-97.

${ }^{8}$ Evans DG, Olarte J, DuPont HL, et al. Enteropathogens associated with pediatric diarrhea in Mexico City. J Pediatr 1977;91:65-8.

9 Shukry S, Zaki AM, DuPont HL, Shoukry I, El Tagi M, Hamed $Z$. Detection of enteropathogens in fatal and potentially fatal diarrhea in Cairo, Egypt. J Clin Microbiol 1986;24:959-62.

10 Aguero ME, Reyes L, Prado V, Orskov F, Cabello FC Enterotoxigenic Escherichia coli in a population of infants with diarrhea in Chile. J Clin Microbiol 1985;22:576-81.

11 Caprioli A, Falbo V, Giraldi V, et al. Produzione di enterotossine e potere invasivo in stipiti di Escherichia Coli isolati da 
bambini con enterite acuta. Giornale di Malattie Infettive e Parassitare 1983;35:796-9.

12 Capano G, Guandalini S, Guarino A, et al. Enteric infections, cow's milk protein intolerance and parenteral infections in 118 consecutive cases of acute diarrhea. Eur J Pediatr 1984;142: 281-5.

13 Bisicchia R, Ciammarughi R, Caprioli A, Falbo V, Ruggeri FM. Toxin production and haemagglutination in strains of Escherichia coli from diarrhoea in Brescia, Italy. J Hyg (Lond) 1985;95: 353-61.

14 Maki M, Vesikari T, Gronroos P. Enterotoxigenic and invasive Escherichia coli as causes of childhood diarrhea in Finland. Acta Paediatr Scand 1980;69:219-24.

15 Brunton J, Hinde D, Langstone C, Gross R, Rowe B, Gurwith M. Enterotoxigenic Escherichia coli in Central Canada. J Clin Microbiol 1980;11:343-8.

16 Pickering LK, Evans DJ, Munoz O, et al. Prospective study of enteropathogens in children with diarrhea in Houston and Mexico. J Pediatr 1978;93:383-8.

17 Loosly J, Gyr K, Stalder GA, et al. Etiology of acute infectious diarrhea in a highly industrialized area of Switzerland. Gastroenterology 1986;88:75-9.

18 Persson BL, Thoren A, Tufvesson B, Walder M. Diarrhea in Swedish infants. Aetiology and clinical appearance. Acta Paediatr Scand 1982;71:909-13.

19 Merson MH, Morris GK, Sack DA, et al. Traveler's diarrhea in Mexico: a prospective study of physicians and family members attending a congress. $N$ Engl J Med 1976;294:1299-305.

20 Giannella RA. Suckling mouse model for detection of heatstable Escherichia coli enterotoxin: characteristics of the model. Infect Immun 1976;14:95-9.

${ }^{21}$ Moseley SL, Hardy JW, Huq MI, Escheverria P, Falkow S. Detection of enterotoxigenic Escherichia coli by DNA-colony hybridization. $J$ Infect Dis 1980;142:892-8.

22 Georges MC, Wachsmuth IK, Birkness KA, Moseley SL, Georges AJ. Genetic probes for enterotoxigenic Escherichia coli isolated from childhood diarrhea in the Central African Republic. J Clin Microbiol 1984;20:59-64.

23 Thompson MR, Brandwein H, Labine-Recke M, Giannella RA. Simple and reliable enzyme-linked immunosorbent assay with monoclonal antibodies for detection of Escherichia coli heatstable enterotoxins. J Clin Microbiol 1984;20:59-64.

24 Guarino A, Capano G, Malamisura B, Alessio M, Guandalini S, Rubino A. Production of Escherichia coli STa-like heat-stable enterotoxin by Citrobacter freundii isolated from humans. J Clin Microbiol 1987;25:110-4.
25 Brandwein H, Deutsch A, Thompson M, Giannella R. Production of neutralizing monoclonal antibodies to Escherichia coli heat-stable enterotoxin. Infect Immun 1985;47:242-6.

26 Taylor WR, Schell WL, Wells JG, et al. A foodborne outbreak of enterotoxigenic Escherichia coli diarrhea. $N$ Engl J Med 1982;306:1093-5.

27 Roweland MGM, Cole TJ, Whitehead RG. A quantitative study into the role of infection in determining nutritional status in Gambian village children. Br J Nutr 1977;37:441-50.

${ }^{28}$ Rosenberg ML, Koplan JP, Wachsmuth JK, et al. Epidemic diarrhea at Crater Lake from enterotoxigenic Escherichia coli: a large waterborne outbreak. Ann Intern Med 1977;86:714-8.

29 DuPont HL, Formal SB, Hornick RB. Pathogenesis of Escherichia coli diarrhea. $N$ Engl J Med 1976;285:1-9.

${ }^{30}$ Black RE, Brown KH, Becker S, Yunus M. Longitudinal studies of infectious diseases and physical growth in rural Bangladesh: I. Patterns of morbidity. Am J Epidemiol 1982;115: 305-14.

31 Cohen MB, Moyer MS, Luttrell M, Giannella RA. The immature rat small intestine exhibits an increased sensitivity and response to Escherichia coli heat-stable enterotoxin. Pediatr Res 1986;20:555-60.

32 Guarino A, Cohen MB, Giannella RA. Small and large intestinal guanylate cyclase activity in children: effect of age and stimulation by Escherichia coli heat-stable enterotoxin. Pediatr Res 1987;25:551-5.

${ }^{33}$ Krejs GJ, Fordtran JS. Diarrhea. In: Sleisinger MH, Fordtran JS, eds. Gastrointestinal disease. 3rd ed. Philadelphia: WB Saunders Company, 1983:258-80.

${ }^{34}$ Merson MH, Black RE. Enterotoxigenic Escherichia coli diarrhea. In: Holme T, Holmgren J, Merson MH, Mollby R, eds. Acute enteric infections in children. New prospects for treatment and prevention. Amsterdam: Elsevier/North Holland Biomedical press, 1983:81-92.

35 Barua B. Diarrhea as a global problem and the WHO programme for its control. In: Holme T, Holmgren J, Merson MH, Mollby R, eds. Acute enteric infections in children. New prospects for treatment and prevention. Amsterdam: Elsevier/ North Holland Biomedical press, 1983:1-6.

Correspondence and requests for reprints to $\mathrm{Dr} \mathrm{A}$ Guarino, Department of Paediatrics, University of Naples, 2nd School of Medicine, Via S Pansini 5, 80131 Naples, Italy.

Accepted 29 November 1988 